\title{
Environmental Violations and Financial Performance of Firms in Korea: Empirical Evidence
}

\author{
Su-hee Hong1), Hyunwook Ryu2)
}

\begin{abstract}
This paper conducted an empirical analysis of the relationship between financial performance and the information on the enterprise value of firms violating environmental regulations. As a result of the test, the influence of the financial data of the firms on enterprise value is not statistically significant. However, beta and volatility, the control variable for stock returns, and the operating margin ratio shows a significant positive effect on stock returns. The industry-adjusted Tobin's Q, a long-term enterprise value, has a significant effect on the number of environmental violations, debt coverage, and ROA ratios. The test result for the number of environment violations shows low explanation power towards the stock returns (a short-term enterprise value) but is significantly correlated to the industry-adjusted Tobin's Q.

Keywords : Violation, Environmental, Regulations, Financial, Performance, Tobin's Q, Beta, Volatility, Stock, Returns
\end{abstract}

\section{Introduction}

It is easy to predict that the social influence of corporations in modern society is considerably large and that such influence will become even greater in the future. The scope of accountability for corporate social influence is also getting bigger with an active attitude.

Global warming, which began in the late 19th century, has not only affected the management decisions of firms that produce goods and services to be used by the global community, but also made it imperative for the firms to take active action for the protection of the environment[1]. Although the company's environmental management activities may require additional investment from the relevant sector, it is necessary to enhance the efficiency of internal resource use in the course of business activities and to create a competitive advantage

Received(July 05, 2019), Review Result(1st: August 02, 2019, 2nd: September 26, 2019), Accepted(November 15, 2019)

1) (Professor) 11644 Dept. Global Trade \& Management, Shinhan University, 95 Hoam-ro, Uijeongbu, Gyeonggi, Korea

email: sue0503@shinhan.ac.kr

2) (Professor, Corresponding Author) 11644 Dept. Global Trade \& Management, Shinhan University, 95 Hoam-ro, Uijeongbu, Gyeonggi, Korea

email: Ryuhw@shinhan.ac.kr 
upon the satisfaction of green consumers with environment-friendly product development. The firms with such competitiveness would ultimately improve business performance by pioneering new-market opportunities. Corporate environmental management activities contribute to avoiding potential future environmental damage, accidents and liabilities. Cost competitiveness due to waste of materials and inefficient processes and compliance with environmental technologies and environmental standards could serve as potential barriers to market entry[2].

This study examines the financial performance of companies violating environmental laws. The objective is to see whether external investors are aware of the importance of environmental issues and how those are reflected in their investment decisions. The study focuses on the correlation of the data from financial statements (which reflect business activities of companies) with stock returns (the capital market assessment data) and industry-adjusted Tobin's Q. With the result of this study, firms would understand how an improved capability of environmental management and conforming to the relevant regulations lead to positive financial outcome. It also expects the firms to come up with a strategic management plan for corporate environmental management.

\section{Changes in Corporate Social Responsibility and Environment Policy}

\subsection{Changes in Environment Policy}

The stakeholder group, including shareholders and creditors, perceives a company's socio-environmental responsibility as a measure of its management efficiency[3]. Thus, failure to conform to corporate environmental responsibility would harm the reputation of the firms and consequently increase the cost. The motives and types of investment in response to environmental problems of a firm can largely be divided into posterior facility investment to comply with the environmental regulation and voluntary investment of the preventive facility to secure a competitive edge in the market[4]. Since 1990, Korea has joined the international trend by enacting and amending the Framework Act on Environmental Policy and related laws for each pollution sector, and significantly strengthened measures to provide loans, tax support and environmental technology to induce businesses to invest in such areas. However, the investment has been made at least amount in regulatory compliance rather than voluntary. In the event a victim occurs due to an environmental violation, the person responsible shall compensate for the damage.

Liability under the Framework Act on Environmental Policy is an obligation. The basis of 
irregular liability is that it conforms with the principle of equitable burden to bear responsibility for the risk liability, that is, the ruler of the risk cause. The exemption does not apply to liability for negligence under the Framework Act on Environmental Policy. Therefore, it is necessary to apply the requirements strictly. Other requirements (illegality, causality, etc) must still be asserted by the plaintiff (the victim). Since 1999, the Ministry of Environment has posted detailed violations and follow-up measures on the status of monthly environmental regulation violators, which represent anti-environmental performance indicators, through nationwide sampling. However, the violation of environmental facilities and regulations is under the jurisdiction of local government, and the local governments are also charge of imposing penalties. The Ministry of Environment has collected and disclosed such information to the extent possible.

\subsection{Literature Review}

Research on the relationship between corporate environmental management and financial performance has been conducted through various methodologies, and various results are mixed. One study shows a positive correlation between environmental performance and financial performance[5-7]. And, another study presents companies with an environmental management system that shows relatively good business performance[8][9]. There is research that identifies the financial performance of environment-friendly firms is superior to that of those not[10]. Some studies have shown that environmental management negatively affects financial performance[11][12]. However, another research concludes that an environmental management system does not have any effect on shareholders or business performance[13][14].

This study examines the relationship between the financial performance and the market evaluation of firms that are relatively neglected in environment management and violate such regulations. The data used covers 87 companies whose violations and counter-measures, were disclosed on the websites of each local government for three years from 2015 to 2017. This study analyzes firms' financial data, market performance, and their relevance to Tobin's Q (industry-adjusted for the long-term value) to see how the violations affect financial data and market assessments.

\section{Data and Analysis}

The purpose of this study is to conduct an empirical analysis of the effect of violation 
information (disclosed on the websites of local governments) on enterprise value. The guidance control system for the pollution discharge industries was established in October, 2002, as local governments have continuously demanded of local transfer of the business of state from a part of local autonomy[15]. Each local government releases details of disposition for environmental violations to its homepage and SAEOL administrative information system. (e-Government portal in Korea) The data is collected from the websites of 230 local governments, 18 metropolitan, provincial governments, and SAEOL administrative system during the period from 2015 to 2017. The entire listed companies are concerned, and we have narrowed it down to those with environmental punishment details for the three years. After sampling companies listed on the Korea Stock Exchange Market by classifying those as environment-friendly firms, the correlation is analyzed between the firms' financial metrics (such as profit margin, sales growth, debt coverage, and return-on-asset ratios) and selected dependent variables (stock returns and industry-adjusted Tobin's Q). The number of violations for these 87 firms is also examined for relevant purposes. Corporate data are extracted from the DataGuide 5.0 from FnGuide Inc. The entity's short-term value is measured by the stock returns. The stock returns are utilized as a proxy variable to identify how an entity's specific information affects its value in the short-term, as all new information about a firm is immediately reflected in its stock price under the efficient market hypothesis.

For identifying an entity's long-term value, Tobin's $Q$ is used. To understand the relationship with the enterprise value proxy in the regression model, control variables of beta and volatility are injected for a firm's size and systematic risk and stock's overall risk respectively[16].

\section{Regression Estimation}

[Table 1] presents descriptive statistics for the financial ratios of the firms violating environmental regulations, the number of violations, and control variables including size, beta and volatility. A firm's stock returns (R) have a strong positive correlation with the beta (Bet), which indicates systematic risk, and the stock price volatility (Vol) also shows a strong positive correlation at a significance level of 0.01 , presented in Table 2. (Bivariate correlation analysis results)

[Table 1] Descriptive Statistics for Variables

\begin{tabular}{|c|r|r|r|r|}
\hline $\mathrm{n}=87$ & \multicolumn{1}{|c|}{ Min. } & \multicolumn{1}{|c|}{ Max. } & \multicolumn{1}{|c|}{ Mean } & \multicolumn{1}{c|}{ S.D. } \\
\hline $\mathrm{R}$ & -52.03 & 176.39 & 1.59 & 38.49 \\
\hline $\mathrm{TQ}$ & -674.86 & 1087.91 & -88.50 & 296.89 \\
\hline
\end{tabular}




\begin{tabular}{|c|r|r|r|r|}
\hline OE & -21.00 & 61.00 & 10.04 & 12.34 \\
\hline GR & -77.00 & 61.00 & 3.29 & 19.39 \\
\hline ROA & -40.71 & 114.54 & 3.41 & 18.82 \\
\hline Debt & 12.00 & 575.00 & 156.23 & 131.27 \\
\hline Size & 18.04 & 25.92 & 21.53 & 1.77 \\
\hline Bet & -0.15 & 1.89 & 0.95 & 0.47 \\
\hline Vol & 0.11 & 1.02 & 0.39 & 0.16 \\
\hline Vio & 1.00 & 11.00 & 2.68 & 2.30 \\
\hline
\end{tabular}

Note,

$R_{t}$. stock returns of a firm at year $\mathrm{t}$; Yearly log return

$T Q_{i}$. Industry-adjusted Tobin's $\mathrm{Q}, \mathrm{TQ}$ of a firm at year $\mathrm{t}$ - $\mathrm{TQ}$ of industry (average)

$O E_{i}$ Profit-margin of a firm at year $\mathrm{t}$

$G R_{i}$. Sales growth of a firm at year $\mathrm{t}$

$R O A_{i}$ : Return-on-asset of a firm at year $\mathrm{t}$

Debi: Debt-coverage of a firm at year $\mathrm{t}$

Size: Total asset of a firm at year $\mathrm{t}$; natural $\log$ value

Bet: Systematic risk $(\beta)$ of a firm at year $\mathrm{t}$

Vol: Volatility (S.D.) for monthly market adjusted return of a firm

Vio: Number of case of environmental violation of a firm

[Table 2] Correlation Analysis

\begin{tabular}{|c|r|r|r|r|r|r|r|r|r|}
\hline & \multicolumn{1}{|c|}{ TQ } & \multicolumn{1}{c|}{ OE } & \multicolumn{1}{c|}{ GR } & \multicolumn{1}{c|}{ ROA } & \multicolumn{1}{c|}{ Debt } & \multicolumn{1}{c|}{ Size } & \multicolumn{1}{c|}{ Bet } & \multicolumn{1}{c|}{ Vol } & \multicolumn{1}{c|}{ Vio } \\
\hline R & -0.047 & 0.155 & 0.168 & -0.103 & 0.014 & 0.05 & $.325^{* *}$ & $.308^{* *}$ & -0.11 \\
\hline TQ & 1 & -0.123 & 0.147 & $-.266^{*}$ & $-.238^{*}$ & -0.196 & 0.014 & 0.092 & 0.043 \\
\hline OE & -0.123 & 1 & -0.028 & 0.093 & $.266^{*}$ & 0.164 & -0.025 & 0.021 & 0.077 \\
\hline GR & 0.147 & -0.028 & 1 & -0.122 & -0.185 & -0.158 & 0.01 & 0.012 & $-.302^{* *}$ \\
\hline ROA & $-.266^{*}$ & 0.093 & -0.122 & 1 & -0.174 & $.267^{*}$ & -0.031 & -0.024 & 0.119 \\
\hline Debt & $-.238^{*}$ & $.266^{*}$ & -0.185 & -0.174 & 1 & 0.033 & $.226^{*}$ & $.313^{* *}$ & 0.186 \\
\hline Size & -0.196 & 0.164 & -0.158 & $.267^{*}$ & 0.033 & 1 & $.283^{* *}$ & -0.145 & $.316^{* *}$ \\
\hline Bet & 0.014 & -0.025 & 0.01 & -0.031 & $.226^{*}$ & $.283^{* *}$ & 1 & $.490^{* *}$ & 0.072 \\
\hline Vol & 0.092 & 0.021 & 0.012 & -0.024 & $.313^{* *}$ & -0.145 & $.490^{* *}$ & 1 & -0.109 \\
\hline Vio & 0.043 & 0.077 & $-.302^{* *}$ & 0.119 & 0.186 & $.316^{* *}$ & 0.072 & -0.109 & 1 \\
\hline
\end{tabular}

* $5 \%,{ }^{* *} 1 \%$ significance level

The industry-adjusted Tobin's $\mathrm{Q}$ has a negative correlation with $\mathrm{ROA}$ and Debt at a significance level of 0.05 , and Size has a positive correlation with ROA and Bet. The number of environmental compliance violations by large firms appears to be higher as these violations have a negative correlation with sales growth at a $1 \%$ confidence level. 
[Table 3] Estimated Results (Effect of financial information on stock returns)

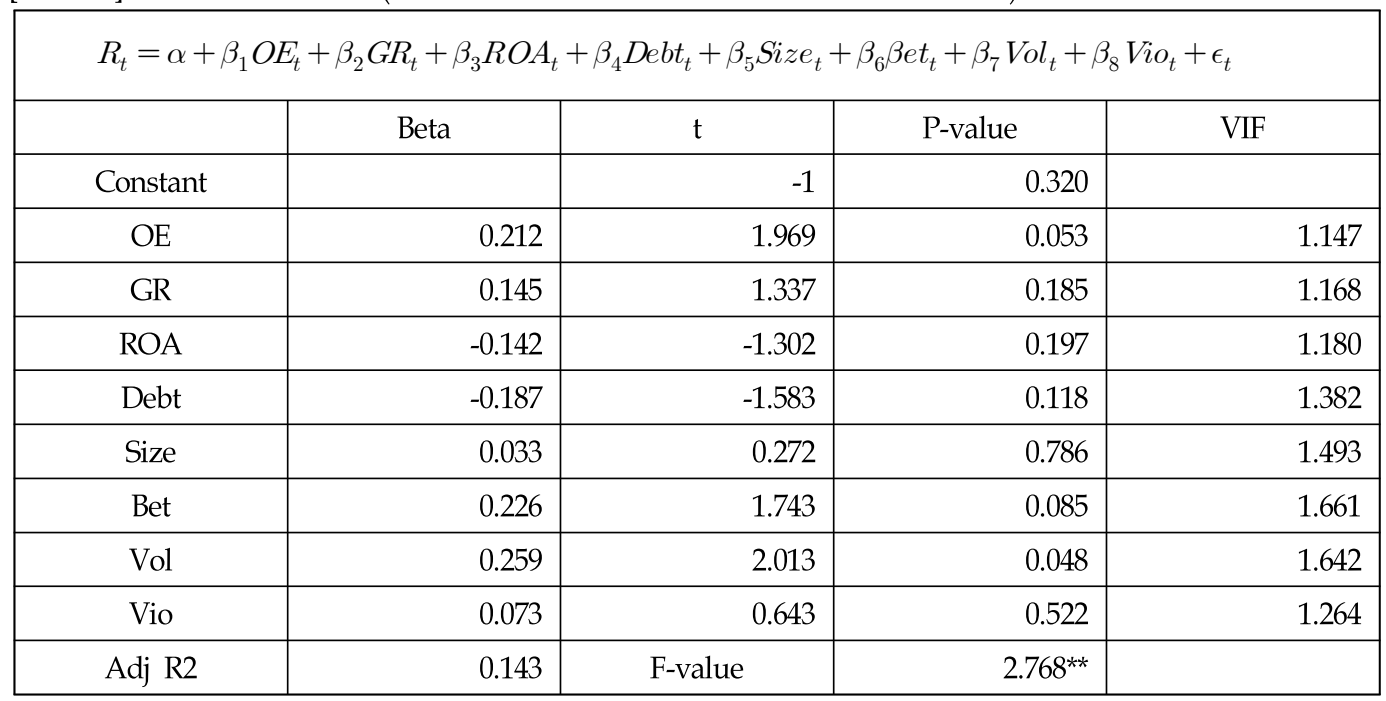

[Table 3] presents the result of regression analysis to examine the effect of financial data on the stock returns, the firm's proxy measurement for short-term value. Only the operating margin ratio(OE), beta(Bet), the control variables for stock returns and volatility(Vol) are found to have a significant amount of effect at the 5 to 10 percent significance level. The VIF values for the variables, as an indicator of multicollinearity, are not problematic, and $14.3 \%$ of adjusted R-square value shows an adequate measure for the model since the F-value is significant at the $5 \%$ level.

The second test attempts to identify the effect of a firm's financial information on Tobin's Q, the enterprise's long-term proxy. At a 1\% significant level, the coefficients of ROA and debt-coverage ratio(Debt) are -0.309 and -0.386 , respectively, and the coefficient of the number of violations(Vio) is -0.247 at the $5 \%$ level. The adjusted R-squared value is $16.5 \%$, and the model fits at the $5 \%$ significant level without multicollinearity among the explanatory variables.

[Table 4] Estimated results (Effect of financial information on Tobin's Q)

\begin{tabular}{|c|r|r|r|r|}
\hline \multicolumn{5}{|c|}{$T Q_{t}=\alpha+\beta_{1} O E_{t}+\beta_{2} G R_{t}+\beta_{3} R O A_{t}+\beta_{4}$ Debt $_{t}+\beta_{5}$ Size $_{t}+\beta_{6} \beta e t_{t}+\beta_{7}$ Vol $_{t}+\beta_{8}$ Vio $_{t}+\epsilon_{t}$} \\
\hline Constant & Beta & $\mathrm{t}$ & \multicolumn{1}{c|}{ P-value } & VIF \\
\hline OE & & 0.750 & 0.455 & 1.147 \\
\hline GR & 0.011 & 0.101 & 0.920 & 1.168 \\
\hline ROA & 0.093 & 0.868 & 0.388 & 1.180 \\
\hline Debt & -0.309 & -2.868 & 0.005 & 1.382 \\
\hline
\end{tabular}




\begin{tabular}{|c|r|r|r|r|} 
& & & \multicolumn{2}{|c|}{ http://dx.doi.org/10.21742/apjcri.2019.12.08 } \\
\hline Size & -0.141 & -1.161 & 0.249 & 1.493 \\
\hline Bet & 0.013 & 0.099 & 0.921 & 1.661 \\
\hline Vol & 0.205 & 1.612 & 0.111 & 1.642 \\
\hline Vio & -0.247 & -2.221 & 0.029 & 1.264 \\
\hline Adj R2 & 0.165 & F-value & $3.103^{* *}$ & \\
\hline
\end{tabular}

\section{Conclusion}

In this study, an empirical analysis is conducted on the financial performance of listed companies in the Korea Stock Exchange market, with failed to conform to environmental regulations between 2015 and 2017. Data on environmental violations are difficult to collect as one would have to verify each detail of the disposition of environmental regulations for the companies through the local government's website and SAEOL administrative system. Thus, this study is limited due to the lack of reliable data.

The academic implications of this study are to obtain reliable data of firms' violation of environmental regulations, and to analyze the relationship with financial performance. The test results show the influence of the financial data of the relevant companies on the corporate value is not significant. Only the beta and volatility variables are positively related to operating profit and stock returns, and debt-coverage ratio, ROA, and the number of violations effect industry adjusted-Tobin's $Q$, the enterprise's long-term value. The results suggest that the violations are not reflected immediately but in the long-term investment decisions. The result also shows that, for the debt-coverage ratio, the higher the ratio, the more negative impact on corporate value. However, it is necessary to collect additional data and analyze with a sophisticated method due to the possible erroneous interpretation of a large-ROA firm with low industry-adjusted Tobin's Q. As the data used in this study are only 3-years of what can be collected in real-term, not enough companies are subject to the analysis, thus, the results hardly explain the market. Further evidence supporting environmental system certification or comparative analysis of environmental law-abiding companies would lead to meaningful research.

\section{References}

[1] S. Hong and M. S. Kim, Market Response for CSR Performance Information - Focused on Additions or Deletions for KRX SRI Index Revisions-, Global Business Administration Review, (2012), Vol.9, No.1, 
pp.65-84, DOI: 10.17092/jibr.2012.9.1.65

[2] M. E. Porter and C. Van der Linde, Toward a New Conception of the Environment-Competitiveness Relationship, Journal of Economic Perspectives, (1995), Vol.9, No.4, pp.97-118, DOI: 10.1257/JEP.9.4.97

[3] G. J. Alexander and R. A. Buchholz, Corporate Social Responsibility and Stock Market Performance, Academy of Management Journal, (1978), Vol.21, No.3, pp.479-486, DOI: 10.5465/255728

[4] Y. K. Jung and S. H. Kim, An Empirical Analysis of the Relationship between Corporate Social Responsibility and Financial Performance: Based on Environmental Equipment Investment, Korean Accounting Journal, (2008), Vol.17, No.4, pp.325-352, UCI: G704-000663.2008.17.4.012

[5] J. H. Hong and I. H. An, An Empirical Study on the Relationship between Environmental and Financial Performance : A case in Korean Manufacturing Sector, Journal of Environmental Policy, (2007), Vol.6, No.4, pp.83-102, DOI: 10.17330/joep.6.4.200712.83

[6] Y. H. Kim, Sun Choi, S. W. Jang, The Effect of Environmental Performance on Financial Performance and Firm Value, Productivity Review, (2018), Vol.32, No.4, pp.33-60.

[7] S. J. Park, J. S. Baek, The Effect of Corporate Social Responsibility on Firm Value: Focusing on KEJI and KSI, Korean Corporation Management Review, (2017), Vol.24. No.2, pp.213-236, UCI: G704-002085.2017.24.2.006

[8] N. Dornall, H. Irene and S. Perry, Do Environmental Management Systems Improve Business Performance in an International Setting?, Journal of International Management, (2008), Vol.14, No.4, pp.364-376, DOI: https://doi.org/10.1016/j.intman.2007.09.006

[9] K. J. Seok, The Impact of Environmental Management System on Business Performance, Tax Accounting Research, (2011), No.28, pp.67-88.

[10] M. A. Cohen, S. A. Fenn, S. Konar, Environmental and Financial Performance : Are They Related?, Vanderbilt University, Owen Graduate School of Management, (1997)

[11] S. Brammer, C. Brooks, S. Pavelin, Corporate Social Performance and Stock Returns: UK Evidence from Disaggregate Measures, Financial Management, (2006), Vol.35, No.3, pp.97-116.

[12] S. Hong, Study of the Financial Ratio and Business Performance of the Environment-related Companies, Global Business Administration Review, (2017), Vol.14, No.5, pp.79-99, DOI: 10.38115/asgba.2017.14.5.79

[13] N. Kimitaka, An Empirical Study of the Initial Adoption of ISO 14001 in Japanese Manufacturing Firms, Ecological Economics, (2009), Vol.68, No.3, pp.669-679, DOI: 10.1016/j.ecolecon.2008.05.023

[14] M. J. Jung, J. H. Park, C. S. Lee, The Effects of Environmental Management Activities on Environmental Business Performance and Interrelationships of Performance, Journal of Finance and Accounting Information, (2015), Vol.15, No.3, pp.21-43.

[15] The Study on the Enforcement Plan for Environmental Pollution Control, Ministry of Environment, (2012)

[16] J. H. Min and B. Kim, Is ESG Effort a Normative Proposition for Sustainability? An Analysis of Different Effects of Firms' ESG efforts by Their Respective Financial Status, Korean Management Science Review, (2019), Vol.36, No.1, pp.17-35, DOI: 10.7737/KMSR.2019.36.1.017 